\title{
A Shock Tube Kinetic Study of Allyl + Allyl and Allyl + OH Recombination Reactions at High Temperatures
}

\author{
Fethi Khaled, Binod Raj Giri* and Aamir Farooq*
}

King Abdullah University of Science and Technology (KAUST), Clean Combustion Research Center, Division of Physical Sciences and Engineering, Thuwal 23955-6900, Saudi Arabia

*Corresponding authors e-mail: $\quad$ Binod.giri@kaust.edu.sa; Aamir.Farooq@kaust.edu.sa

\section{Colloquium: Gas-Phase Reaction Kinetics}

Word Count (method1):

\begin{tabular}{|l|l|}
\hline Main text & 3636 \\
\hline Equations: 9 & 83 \\
\hline References: 27 & 506 \\
\hline Tables: 0 & 0 \\
\hline Figures: 5 & 1557 \\
\hline Total & 5782 \\
\hline
\end{tabular}

This manuscript contains Supplementary Material. 


\section{Abstract}

In this work, we investigated the self-reaction of allyl radicals and its cross-reaction with hydroxyl by employing shock tube and laser absorption techniques. We carried out the experiments behind reflected shock waves over the temperature range of $800-1200 \mathrm{~K}$ and pressures of $1.1-2.5$ bar. We generated allyl $\left(\mathrm{C}_{3} \mathrm{H}_{5}\right)$ and $\mathrm{OH}$ radicals by fast thermal decomposition of allyl iodide $\left(\mathrm{C}_{3} \mathrm{H}_{5} \mathrm{I}\right)$ and tert-butyl hydroperoxide (TBHP), respectively, and monitored reaction progress by detecting $\mathrm{OH}$ near $306.69 \mathrm{~nm}$ and $\mathrm{C}_{3} \mathrm{H}_{5}$ near $220 \mathrm{~nm}$ using UV laser absorption. At the detection wavelength, we measured the temperature dependence of the absorption cross-sections of $\mathrm{C}_{3} \mathrm{H}_{5}$ and $\mathrm{C}_{3} \mathrm{H}_{5} \mathrm{I}$. Rate coefficient for the selfrecombination reaction of allyl radicals showed a small negative temperature dependance, and no noticeable fall-off behavior over $1.15-1.96$ bar, giving a mean value of $k_{\mathrm{C} 3 \mathrm{H} 5+\mathrm{C} 3 \mathrm{H} 5}=(1.0 \pm 0.2) \times 10^{-11}$ $\mathrm{cm}^{3}$ molecule $\mathrm{s}^{-1}$. Likewise, the cross-reaction of allyl and $\mathrm{OH}$ radicals did not exhibit discernible presure and temperature dependance under our experimental conditions, indicating a barrierless reaction, and an average value of $k_{\mathrm{C} 3 \mathrm{H} 5}+\mathrm{OH}=(9.3 \pm 0.7) \times 10^{-11} \mathrm{~cm}^{3}$ molecule $\mathrm{e}^{-1} \mathrm{~s}^{-1}$ best illustrates our measured rate coefficients. These measurements represent the first direct experimental determinations of the rate coefficients for these important radical-radical reactions at high temperatures and pressures.

Keywords: Allyl; Hydroxyl; Recombination reaction; Resonantly stibilized radicals; Shock tube, Laser UV absorption. 


\section{Introduction}

Aromatic species are the building blocks of polycyclic aromatic hydrocarbons (PAHs) which ultimately produce soot under combustion relevant conditions. Resonantly stabilized hydrocarbon radicals such as propargyl $\left(\mathrm{C}_{3} \mathrm{H}_{3}\right)$ and allyl $\left(\mathrm{C}_{3} \mathrm{H}_{5}\right)$ play important roles in the formation of aromatic hydrocarbons $[1,2]$. Due to their relatively high resonance stabilization energies of $\sim 50 \mathrm{~kJ} / \mathrm{mol}$ and $\sim 61 \mathrm{~kJ} / \mathrm{mol}$ for $\mathrm{C}_{3} \mathrm{H}_{3}$ and $\mathrm{C}_{3} \mathrm{H}_{5}$, respectively [3], these are thermodynamically stable and exhibit quite a slow reaction with $\mathrm{O}_{2}$ under combustion conditions [4]. Consequently, such resonantly stabilized radicals can accumulate to high concentrations in reactive hydrocarbon systems, and their self-recombination or cross radical-radical reactions become dominant loss channels at high temperatures.

There are quite a few experimental studies on the self-recombination reaction of allyl radicals (see a comprehensive review in Table S1 of Supplementary Materials). Most of these studies are limited to temperatures lower than $1000 \mathrm{~K}$ except a recent laser densitometry study $(T=900-1700 \mathrm{~K}, P \leq 0.16$ bar $)$ of Lynch et al. [5] and a single-pulse shock tube speciation study ( $T=650-1300 \mathrm{~K}, P \leq 10$ bar) of Fridlyand et al. [6]. Most previous works employed UV absorption of allyl radicals to follow the kinetics of self-recombination reaction of allyl radicals. Except a low-pressure pyrolysis study of Rossi et al.[7], all literature experimental rate coefficients below $800 \mathrm{~K}$ show no pressure effects indicating the reaction is close to the high-pressure limit. These data show a slight negative temperature dependence, though the rate coefficient results are still quite close to $(2.7 \pm 0.8) \times 10^{-11} \mathrm{~cm}^{3}$ molecule $\mathrm{s}^{-1}$ determined by Selby et al. [8] at $298 \mathrm{~K}$. Matsugi et al. [9] questioned the accuracy of these rate data for $T \geq 298 \mathrm{~K}$ arguing that the measurements might have been affected by the assumption of temperature-independent values for absorption cross-section of allyl radicals. For this reason, Matsugi et al. [9] first measured the temperaturedependent absorption cross-section of allyl radicals at $402.9 \mathrm{~nm}$, and then determined the rate coefficient of allyl recombination over the temperature range of $295-800 \mathrm{~K}$ and pressures of $20-200$ Torr. Their 
measured rate data show good agreement with earlier studies, indicating that the assumption of temperature-independence of the absorption coefficient of allyl radicals is probably valid. Moreover, Matsugi et al. [9] did not observe any fall-off effects. Since the low-pressure / high-temperature measurements of Throssel [10], Golden et al. [11] and Rossi et al. [7] may have indicated fall-off effects, Matsugi et al. [9] further performed RRKM/Master-Equation calculations to predict the temperature- and pressure- dependent rate coefficients of allyl recombination. Their theoretical predictions capture the lowpressure data of Throssel [10] and Rossi et al. [7] reasonably well, and exhibit pronounced pressuredependence above $500 \mathrm{~K}$. However, their computed $k_{\infty}(T)$ show much steeper inverse temperaturedependence than those of the experiments, and their predicted rates overestimate Lynch et al. [5] data by at least a factor of 2 at high temperatures. The discrepancy between theoretical calculations and experiments warrants additional studies for allyl + allyl reaction at high temperatures.

Both $\mathrm{C}_{3} \mathrm{H}_{5}$ and $\mathrm{OH}$ radicals are important combustion species. The reaction of these radicals can lead to the formation of enol which has been detected in flames $[12,13]$. Therefore, understanding of the reaction pathways for the removal of these radicals under combustion conditions is crucial. To the authors' knowledge, there are no previous experimental studies which report rate coefficients for allyl $+\mathrm{OH}$ reaction. For this important reaction, most chemical kinetic models currently rely on Tsang's [14] estimated rate (error bounds of factor of 3). This clearly evokes an investigation for this reaction.

The current work is aimed at measuring high-temperature rate coefficients for allyl recombination and allyl $+\mathrm{OH}$ reactions by employing shock tube and UV laser absorption techniques. Detailed kinetic analysis is performed to extract accurate values of rate coefficients from the measured species profiles. We also report rate coefficients for allyl iodide decomposition, as well as absorption cross-sections of allyl iodide and allyl. 


\section{Experimental Details}

Allyl $\left(\mathrm{C}_{3} \mathrm{H}_{5}\right)$ and hydroxyl $(\mathrm{OH})$ radicals were generated thermally behind reflected shock waves by their corresponding well-known precursors, allyl iodide $\left(\mathrm{C}_{3} \mathrm{H}_{5} \mathrm{I}\right)$ [15] and tert-butyl hydroperoxide $\left(\left(\mathrm{CH}_{3}\right)_{3}-\mathrm{C}\right.$ $\mathrm{O}-\mathrm{OH})[16]$, via following reactions:

$$
\begin{array}{lr}
\mathrm{C}_{3} \mathrm{H}_{5} \mathrm{I} & \mathrm{R}_{1 \mathrm{a}} \\
& \rightarrow \mathrm{C}_{3} \mathrm{H}_{5}+\mathrm{I} \\
& \mathrm{R} \\
\left(\mathrm{CH}_{3}\right)_{3}-\mathrm{C}-\mathrm{O}-\mathrm{OH} \rightarrow \mathrm{CH}_{3} \mathrm{C}(\mathrm{O}) \mathrm{CH}_{3}+\mathrm{OH}+\mathrm{CH}_{3} & \mathrm{R}_{2}
\end{array}
$$

Elimination of hydrogen iodide (HI) from $\mathrm{C}_{3} \mathrm{H}_{5} \mathrm{I}, \mathrm{R}_{1 \mathrm{~b}}$, plays a minor role because the branching ratio $\left(k_{1 \mathrm{~b}} / k_{1 \mathrm{a}}\right)$ for this channel was previously found to be 0.003 [6]. This value of the branching ratio is consistent with an upper limit of $\sim 0.01$, reported by Lynch et al. [5]. Therefore, one can safely rule out reaction $\mathrm{R}_{1 \mathrm{~b}}$. Furthermore, I atoms produced via reaction $\mathrm{R}_{1 \mathrm{a}}$ remain virtually inert under shock tube conditions [17] which makes $\mathrm{C}_{3} \mathrm{H}_{5} \mathrm{I}$ an excellent thermal source of $\mathrm{C}_{3} \mathrm{H}_{5}$ radicals.

All experiments were carried out behind reflected shock waves. As details of the shock tube and $\mathrm{OH}$ diagnostic can be found elsewhere [18, 19]; only a brief description of the detection system is given here. A schematic of the experimental set up is shown in Fig. 1. Two pairs of quartz windows mounted $2 \mathrm{~cm}$ away from the shock tube end-wall were used to propagate $307 \mathrm{~nm}$ light for $\mathrm{OH}$ detection and $220 \mathrm{~nm}$ to detect $\mathrm{C}_{3} \mathrm{H}_{5}$. 


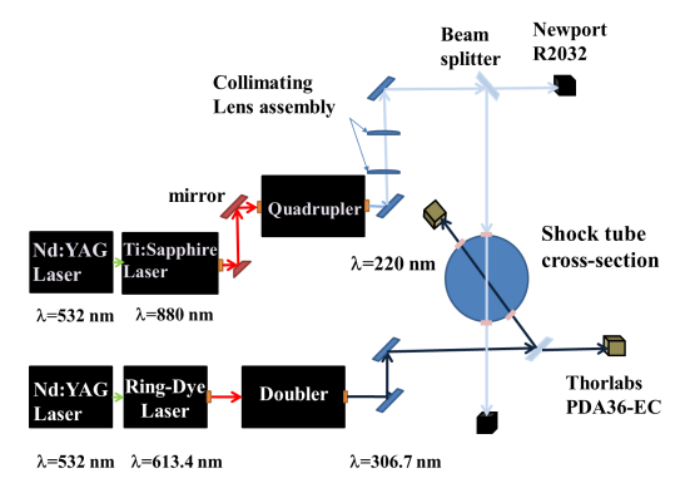

Figure 1: A schematic of the optical set up for simultaneous detection of allyl and $\mathrm{OH}$ radicals.

For OH radical detection, we employed a narrow width Spectra-physics dye laser system to generate ultraviolet (UV) light at $307 \mathrm{~nm}$ utilizing the external frequency doubling of red light (614 $\mathrm{nm})$ produced by a ring-dye $\mathrm{cw}$ laser. We used a Millennia pump laser at $532 \mathrm{~nm}$ to pump the righ-dye $\mathrm{cw}$ laser. We tuned the UV light to the center $(306.6868 \mathrm{~nm})$ of the well-characterized R1(5) absorption line in the $(0,0)$ absorption band of $\mathrm{A}^{2} \Sigma^{+} \leftarrow \mathrm{X}^{2} \Pi$ transition of $\mathrm{OH}$ radical. For this particular electronic excitation, we employed the line strength and line shape functions from the work of Hanson's group [20, 21] to calculate the absorption coefficients of $\mathrm{OH}$ radicals within an uncertainty of 3\%. Allyl exhibits a broad UV absorption spectrum in the wavelength range of $\lambda=210-240 \mathrm{~nm}$ with a peak absorption cross-section of $\sigma_{\max }(298 \mathrm{~K})=5.7 \times 10^{-17} \mathrm{~cm}^{2}$ molecule ${ }^{-1}$ near $\lambda_{\max }=223 \mathrm{~nm}$ [22]. Bergh et al. [22] attributed this strong UV absorption of allyl radicals to the $B\left({ }^{2} B_{1}\right) \leftarrow X\left({ }^{2} A_{2}\right)$ electronic transition. We monitored $\mathrm{C}_{3} \mathrm{H}_{5}$ radicals near $220 \mathrm{~nm}$ by utilizing a Ti:Sapphire laser system (Spectra-Physics Tsunami 3950) coupled to a fourthharmonic generator. A cw solid-state Nd:YAG laser (532 nm, 15 Watts) was used to pump the Ti-Sapphire laser. With proper broadband optics, Ti-Sapphire laser can deliver tunable output in the wavelength range of 690 to $1080 \mathrm{~nm}$. In this work, we operated the Ti-Sapphire laser at $880 \mathrm{~nm}$ with a pulse width of $2 \mathrm{ps}$ and $80 \mathrm{MHz}$ repetition rate, which makes the laser output to be pseudo-cw at the photo-detector bandwidth of $900 \mathrm{kHz}$. The output power of the laser beam was $\sim 2.6 \mathrm{~W}$ at $880 \mathrm{~nm}$, and $\sim 25 \mathrm{~mW}$ at $220 \mathrm{~nm}$. The 
linewidth of the laser was $~ 1 \mathrm{~nm}$ at $880 \mathrm{~nm}$ (as measured by Ocean Optics spectrometer USB2000+) and calculated to be $\sim 0.25 \mathrm{~nm}$ at $220 \mathrm{~nm}$ which is much less than that of allyl radical (>10 nm, [22]). Two silicon photodetectors (Newport R2032) equipped with a laser-line filter near $220 \mathrm{~nm}$ were used to measure the laser intensity before and after the shock tube. The noise of the laser beam after commonmode-rejection was less than $0.1 \%$ of the signal.

The chemicals used were: $70 \%$ solution of TBHP in water, allyl iodide ( $\geq 98 \%$ purity), and argon (99.999\% purity). Gas mixtures containing radical precursors $\left(\mathrm{C}_{3} \mathrm{H}_{5} \mathrm{I}\right.$ or $\left.\mathrm{C}_{3} \mathrm{H}_{5} \mathrm{I}+\mathrm{TBHP}\right)$ in argon were prepared manometrically in a 24-litre Teflon-coated stainless-steel vessel equipped with a magneticallydriven stirrer. The mixtures were left to homogenize for at least one hour. Prior to gas mixture preparation, the mixing vessel was turbo-pumped down to $<10^{-5}$ Torr. Capacitance pressure gauge (MKS Baratron) of 0-20 Torr range was used to accurately measure partial pressures of radical precursors. During these experiments, no heating of the shock tube and/or mixing vessel or manifold was involved.

\section{Results and Discussion}

\subsection{Absorption Cross-Sections of $\mathrm{C}_{3} \mathrm{H}_{5} \mathrm{I}$ and $\mathrm{C}_{3} \mathrm{H}_{5}$}

A series of shock tube experiments were performed over $794-1172 \mathrm{~K}$ and $1.15-2.5$ bar with $\mathrm{C}_{3} \mathrm{H}_{5} \mathrm{I} / \mathrm{Ar}$ mixtures by monitoring $\mathrm{C}_{3} \mathrm{H}_{5}$ radicals at $220 \mathrm{~nm}$. Figure $1 \mathrm{~S}$ (Supplementary Materials) shows a typical laser transmission profile, illustrating very high signal-to-noise ratio. We observed absorption interference caused by $\mathrm{C}_{3} \mathrm{H}_{5} \mathrm{I}$ at $220 \mathrm{~nm}$, in accordance with previous studies [23, 24] which reported an absorption cross section of $\sigma_{\mathrm{C} 3 \mathrm{H} 5 \mathrm{I}, 220 \mathrm{~nm}}=1.07 \times 10^{-17} \mathrm{~cm}^{2} /$ molecule at $296 \mathrm{~K}$ and 1 bar. The interference by $\mathrm{C}_{3} \mathrm{H}_{5} \mathrm{I}$ needs to be accounted for to reliably extract desired kinetic information. We recorded the absorption of allyl iodide $\left(\mathrm{C}_{3} \mathrm{H}_{5} \mathrm{I}\right)$ at pre-shock and incident-shock conditions $\left(T \leq 700 \mathrm{~K}\right.$ and $P \leq 0.5$ bar) where $\mathrm{C}_{3} \mathrm{H}_{5} \mathrm{I}$ 
is thermally stable. Using Beer-Lambert law, we determined absorption cross-sections of $\mathrm{C}_{3} \mathrm{H}_{5} \mathrm{I}$ which did not exhibit any temperature dependence, and agreed with previous values $[23,24]$ within $\pm 10 \%$ (see Fig. $2 \mathrm{~S}$ in Supplementary Materials). Therefore, we used temperature-independent value of $\sigma_{\mathrm{C} 3 \mathrm{H} 5 \mathrm{I}, 220 \mathrm{~nm}}=1.07$ $\times 10^{-17} \mathrm{~cm}^{2} /$ molecule to evaluate our high-temperature data.

As stated earlier, the reliability of rate coefficients for allyl recombination depends on the accuracy of absorption cross-sections. There are no previous studies which measured temperature-dependent absorption cross-section of allyl radicals at $220 \mathrm{~nm}$. This was accomplished in the current work by recording the absorption of allyl radicals at $220 \mathrm{~nm}$ after fast thermal decomposition of $\mathrm{C}_{3} \mathrm{H}_{5} \mathrm{I}(\tau \leq 4 \mu \mathrm{s}$ for $T \geq 1000 \mathrm{~K}, P \geq 1.5$ bar [6]). The measured absorbance time-histories followed second-order kinetics with respect to allyl concentration. The absorbance at time zero was easily obtained by extrapolation of reciprocal absorbance vs time plot. Absorption cross-sections of allyl $\left(\sigma_{\mathrm{C} 3 \mathrm{H} 5,220 \mathrm{~nm})}\right)$ were obtained by applying Beer Lambert law and equating $\left[\mathrm{C}_{3} \mathrm{H}_{5}\right]_{0}=\left[\mathrm{C}_{3} \mathrm{H}_{5}\right]_{0}$. Our measurements were kept below $1200 \mathrm{~K}$ because allyl radicals begin dissociating in appreciable amounts beyond $1200 \mathrm{~K}\left(t_{1 / 2} \sim 725 \mu \mathrm{s}[15]\right)$. We obtained an average value of $\sigma_{\mathrm{C} 3 \mathrm{H} 5,220 \mathrm{~nm}}=(3.1 \pm 0.3) \times 10^{-17} \mathrm{~cm}^{2}$ molecule $^{-1}$ over $950-1200 \mathrm{~K}$. Uncertainty in measured absorption cross-section was caused mainly due to uncertainties in the mixture composition $( \pm 5 \%)$ and location of time zero $( \pm 2 \mu \mathrm{s})$. Earlier measurements $[22,23,25]$ showed some scatter $\left(\sim 5.0\right.$ to $7.2 \times 10^{-17} \mathrm{~cm}^{2}$ molecule $\left.{ }^{-1}\right)$ for the absorption cross-section of allyl at $220 \mathrm{~nm}$. These room-temperature values are roughly a factor of two higher than our high-temperature data. Combining our determination with room-temperature values from Jenkin et al. [23] and Van den Bergh and Callear [22], we recommend $\sigma_{\mathrm{C} 3 \mathrm{H} 5,220 \mathrm{~nm}}(T)=5.7 \times 10^{-17}(T / 298)^{-0.45} \mathrm{~cm}^{2}$ molecule ${ }^{-1}$ over $298-1200 \mathrm{~K}$ (see Fig. 2). The absorption cross-section of allyl near $220 \mathrm{~nm}$ is found to be almost two orders of magnitude higher than the value at $403 \mathrm{~nm}$ reported by Matsugi et al. [9]. 


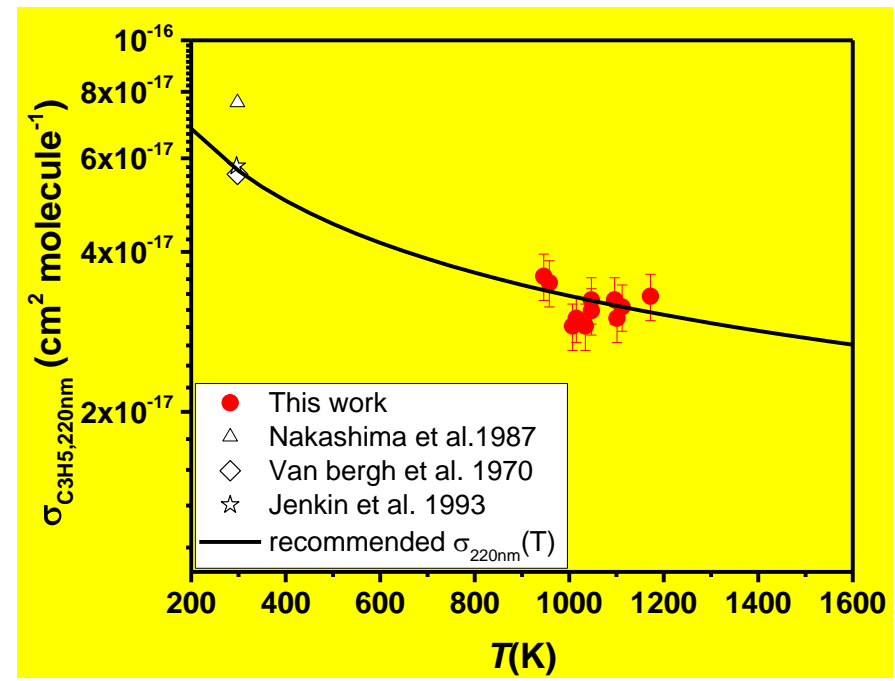

Figure 2: Absorption cross-sections of allyl radicals. Black line represents our recommended value given by $\sigma_{\mathrm{C} 3 \mathrm{H} 5,220 \mathrm{~nm}}(T)=5.7 \times 10^{-17}(T / 298)^{-0.45} \mathrm{~cm}^{2}$ molecule ${ }^{-1}$ over $298-1200 \mathrm{~K}$.

\section{2 $\mathrm{C}_{3} \mathrm{H}_{5}+\mathrm{C}_{3} \mathrm{H}_{5}$ Reaction}

Self-recombination reaction of allyl radicals proceeds by a barrierless addition to yield 1,5-hexadiene, $\mathrm{R}_{3 \mathrm{a}}$, followed by several isomerization and dissociation channels [9]. The disproportionation channel, $\mathrm{R}_{3 b}$, has negligible contribution $\left(k_{3 \mathrm{~b}} / k_{3 \mathrm{a}}=0.003\right)$ [6]. Back dissociation of 1,5-hexadiene $\left(\mathrm{R}_{-3 \mathrm{a}}\right)$ becomes important at high temperatures, e.g., $k_{\infty}=36 \mathrm{~s}^{-1}$ at $900 \mathrm{~K}$ [5].

$$
\begin{aligned}
\mathrm{C}_{3} \mathrm{H}_{5}+\mathrm{C}_{3} \mathrm{H}_{5} & \leftarrow 1,5-\mathrm{C}_{6} \mathrm{H}_{10} & \mathrm{R}_{3 \mathrm{a}} \text { and } \mathrm{R}_{-3 \mathrm{a}} \\
& \rightarrow a-\mathrm{C}_{3} \mathrm{H}_{4}+\mathrm{C}_{3} \mathrm{H}_{6} & \mathrm{R}_{3 \mathrm{~b}}
\end{aligned}
$$



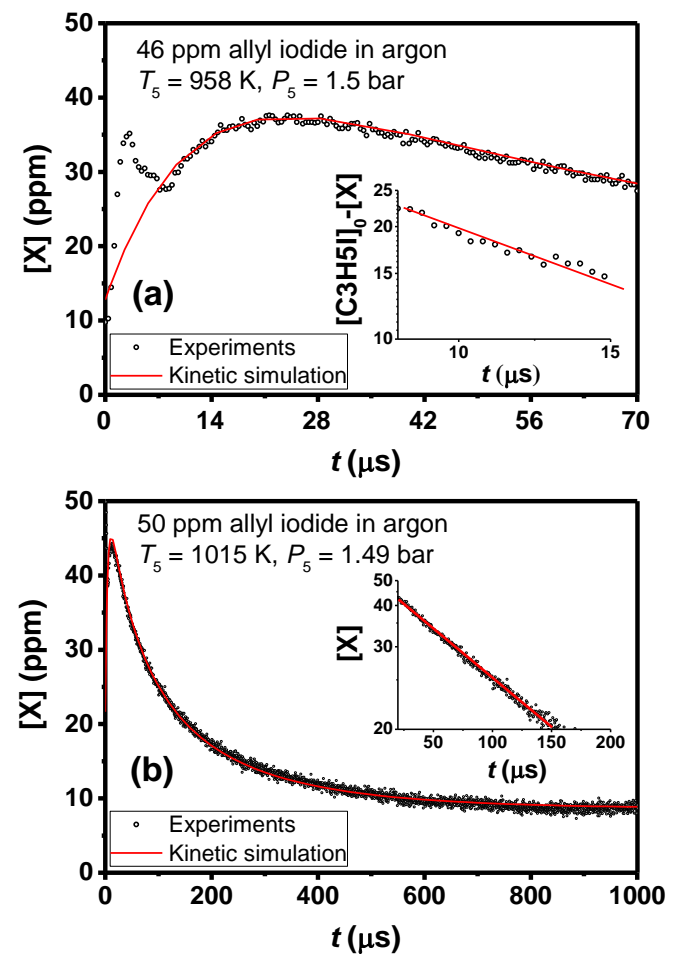

Figure 3: Measured time-histories of allyl radicals at $220 \mathrm{~nm}$. The vertical axis of the insets is in (a) $\log$ scale and (b) reciprocal scale.

Figure 3 plots allyl time-histories at two representative conditions which show complex kinetic behavior due to the characteristics of reactions $\mathrm{R}_{1 \mathrm{a}}, \mathrm{R}_{3 \mathrm{a}}$ and $\mathrm{R}_{-3 \mathrm{a}}$. Therefore, a careful analysis of the data is required. Differential rate laws for major species can be expressed as:

$$
\begin{aligned}
& \frac{d\left[C_{3} H_{5}\right]}{d t}=k_{1 a}\left[C_{3} H_{5} I\right]-2 k_{3 a}\left[C_{3} H_{5}\right]^{2}+2 k_{-3 a}\left[1,5 C_{6} H_{10}\right] \\
& \frac{d\left[C_{3} H_{5} I\right]}{d t}=-k_{1 a}\left[C_{3} H_{5} I\right] \\
& \frac{d\left[1,5 C_{6} H_{10}\right]}{d t}=k_{3 a}\left[C_{3} H_{5}\right]^{2}-k_{-3 a}\left[1,5 C_{6} H_{10}\right]
\end{aligned}
$$

With $\left[\mathrm{C}_{3} \mathrm{H}_{5} \mathrm{I}\right]=\left[\mathrm{C}_{3} \mathrm{H}_{5} \mathrm{I}\right]_{0} \exp \left(-k_{1 \mathrm{a}} \mathrm{t}\right)$ and $\left[1,5 \mathrm{C}_{6} \mathrm{H}_{10}\right]=\left(\left[\mathrm{C}_{3} \mathrm{H}_{5} \mathrm{I}\right]_{0}-\left[\mathrm{C}_{3} \mathrm{H}_{5} \mathrm{I}\right]-\left[\mathrm{C}_{3} \mathrm{H}_{5}\right]\right) / 2$, Eq. 1 becomes:

$$
\frac{d\left[C_{3} H_{5}\right]}{d t}=\left(k_{1 a}-k_{-3 a}\right)\left[C_{3} H_{5} I\right]_{0} \exp \left(-k_{1 a} t\right)+k_{-3 a}\left[C_{3} H_{5} I\right]_{0}-2 k_{3 a}\left[C_{3} H_{5}\right]^{2}-k_{-3 a}\left[C_{3} H_{5}\right]
$$


Since both $\mathrm{C}_{3} \mathrm{H}_{5}$ and $\mathrm{C}_{3} \mathrm{H}_{5} \mathrm{I}$ absorb at $220 \mathrm{~nm}$, we define a quantity $[X]$ to express our experimentally measured time histories:

$[X]_{\text {measured }}=\left[C_{3} H_{5}\right]+\varphi\left[C_{3} H_{5} I\right]$

where $\varphi$ is the ratio of absorption cross-sections of $\mathrm{C}_{3} \mathrm{H}_{5} \mathrm{I}$ and $\mathrm{C}_{3} \mathrm{H}_{5}$. Thus, it leads to:

$$
\begin{aligned}
\frac{d[X]}{d t}=((1-\varphi) & \left.k_{1 a}-k_{3 a}\right)\left[C_{3} H_{5} I\right]_{0} \exp \left(-k_{1 a} t\right)+k_{-3 a}\left[C_{3} H_{5} I\right]_{0}-2 k_{3 a}[X]^{2} \\
& -\left(k_{-3 a}-4 k_{3 a} \varphi\left[C_{3} H_{5} I\right]_{0} \exp \left(-k_{1 a} t\right)\right) \cdot X+k_{-3 a} \varphi\left[C_{3} H_{5} I\right]_{0} \exp \left(-k_{1 a} t\right) \\
& -2 k_{3 a} \varphi^{2}\left[C_{3} H_{5} I\right]_{0}^{2} \exp \left(-2 k_{1 a} t\right)
\end{aligned}
$$

The unknowns $\left(k_{1 \mathrm{a}}, k_{3 \mathrm{a}}\right.$ and $\left.k_{-3 \mathrm{a}}\right)$ were determined by iteratively fitting experimental $[X]$ time-histories. For early stage of the reaction and low temperatures, our profiles are sensitive mostly to $\mathrm{C}_{3} \mathrm{H}_{5} \mathrm{I}$ decomposition $\left(\mathrm{R}_{1 \mathrm{a}}\right)$. Therefore, for early stage of the reaction, Eq. 6 reduces to:

$[X]-\left[C_{3} H_{5} I\right]_{0}=(\varphi-1)\left[C_{3} H_{5} I\right]_{0} \exp \left(-k_{1 a} t\right)$

Thereafter, $k_{1 \mathrm{a}}$ and $\varphi$ are obtained from the slope and intercept of the $\ln \left([X]-\left[C_{3} H_{5} I\right]_{0}\right)$ vs time plot (inset of Fig. 3(a)), respectively. We note that the absorption signal is affected by schlieren spike for few microseconds after time zero (passage of reflected shock).

In cases where allyl self-reaction $\left(\mathrm{R}_{3 \mathrm{a}}\right)$ dominates, e.g., later stage of Fig. 3(a) and early stage of Fig. 3(b), the decay is purely second order (as demonstrated in the inset of Fig. 3(b)). For such conditions, the measured profiles are sensitive only to $\mathrm{R}_{3 \mathrm{a}}$, and Eq. (6) becomes:

$\frac{1}{[X]}=\frac{1}{\left[C_{3} H_{5} I\right]_{0}}+2 \cdot k_{3 a} \cdot t$ 
Thereafter, $k_{3 \mathrm{a}}$ is obtained from the slope of $\frac{1}{[X]}$ vs time plot.

Finally, at high temperatures and late reaction times, equilibrium is established for reaction $\mathrm{R}_{3 a}$. Consequently, $k_{-3 \text { a }}$ can be deduced according to Eq. (9):

$K=\frac{k_{3 a}}{k_{-3 a}}=\frac{\left(\left[C_{3} H_{5} I\right]_{0}-[X]\right)}{2 \cdot[X]^{2}}$

Additionally, we employed detailed kinetic mechanism [5] fitting of the experimental profiles employing $k_{1 \mathrm{a}}, k_{3 \mathrm{a}}$ and $k_{-3 \mathrm{a}}$ values determined through Eqs. 7-9. Those fits are shown by red lines in Fig. 3. A sensitivity analysis (see Fig. 3S of Supplementary Materials) showed that allyl concentration is only sensitive to reactions $\mathrm{R}_{1 \mathrm{a}}, \mathrm{R}_{3 \mathrm{a}}$ and $\mathrm{R}_{-3 \mathrm{a}}$, and this is true for all experimental conditions $(P=1.15-2.5$ bar, $T=794-1200 \mathrm{~K})$ of this work. The determined rate coefficients $\left(k_{1 \mathrm{a}}, k_{3 \mathrm{a}}, k_{-3 \mathrm{a}}\right)$ are compiled in Tables $2 \mathrm{~S}$ (Supplementary Material), and compared with literature data for $k_{3 \mathrm{a}}, k_{1 \mathrm{a}}$, and $k_{-3 \mathrm{a}}$ in Fig. 4 , Fig. 4S and Fig. 5S, respectively. Our measured rate data for $k_{1 \mathrm{a}}$ and $k_{-3 \mathrm{a}}$ compare very well with the theoretical predictions of Lynch et al. [5] (see Figs. 4S - 5S of Supplementary Materials). As these measurements are not the primary objective of this study, we focus our discussion on $k_{3 a}$.

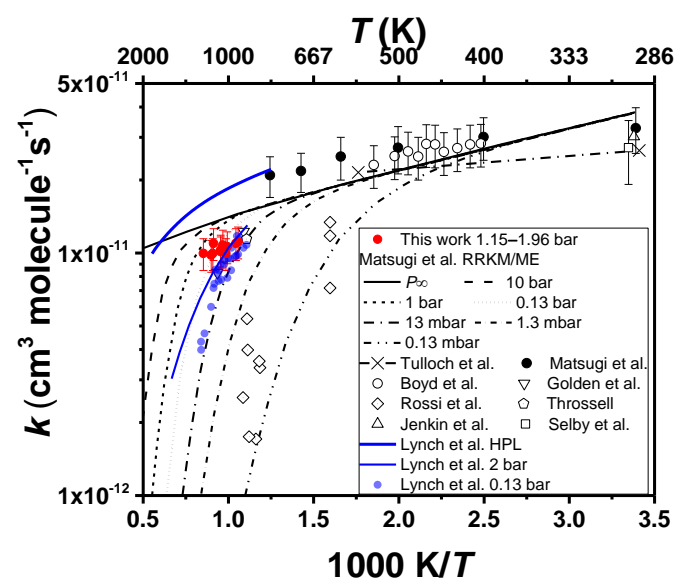

Figure 4: Arrhenius plot for the rate coefficient $\left(k_{3 \mathrm{a}}\right)$ of allyl self-recombination. Figure adopted from Matsugi et al. [8] to compare with literature data. 
As can be seen in Fig. 4, our measured rate coefficients for allyl self-recombination exhibited slight negative temperature dependence over $950-1200 \mathrm{~K}$ and $1.15-1.96$ bar. Under these conditions, we determined a mean value of $(1.0 \pm 0.2) \times 10^{-11} \mathrm{~cm}^{3}$ molecule $\mathrm{e}^{-1} \mathrm{~s}^{-1}$ for $k_{3 \mathrm{a}}$. No obvious fall-off effects were observed within our narrow pressure range. Our rate coefficients are close (within 40\%) to the predicted high-pressure limit of Matsugi et al. [9]. Our high-temperature data matched excellently with RRKM/ME calculations of Matsugi et al. [9] for 1 bar. However, these calculations under-predicted our lower temperature data by $\sim 40 \%$ but captured the trend reasonably well. Below $1000 \mathrm{~K}$, our data $(P=1.15-$ 1.96 bar) matched very well with the 120 Torr data of Lynch et al. [5] indicating that fall off effects are not very critical for those conditions. Furthermore, Gorin-type RRKM calculations of Lynch et al. [5] captured our data excellently but predicted quite severe fall-off at high temperatures which is not supported by our experimental observations. The origin of the discrepancy between these theoretical studies may lie in the accuracy of the potential energy surface and the value of collisional energy transfer parameter, $\langle\Delta \mathrm{E}\rangle_{\text {down }}$. Our measured rate coefficients will add value to the existing dataset, and help tune future theoretical models to accurately predict pressure- and temperature- dependence of allyl selfrecombination reaction.

\section{3 $\mathrm{C}_{3} \mathrm{H}_{5}+\mathrm{OH}$ Reaction}

The attack of $\mathrm{OH}$ on either the radical site or the terminal-vinylic site of allyl radical results in the formation of allyl alcohol, reaction $\mathrm{R}_{4 \mathrm{a}}$. This reaction is highly exothermic; $\Delta_{\mathrm{r}, 298 \mathrm{~K}} H^{\circ} \sim-334 \mathrm{~kJ} / \mathrm{mol}$, based on $\Delta_{\mathrm{f}, 298 \mathrm{~K}} H^{\circ}\left(\mathrm{C}_{3} \mathrm{H}_{5}\right)=171 \pm 3, \Delta_{\mathrm{f}, 298 \mathrm{~K}} H^{\circ}(\mathrm{OH})=38.99$ and $\Delta_{\mathrm{f}, 298 \mathrm{~K}} H^{\circ}\left(\mathrm{C}_{3} \mathrm{H}_{5} \mathrm{OH}\right)=-123.6 \pm 1.5$ in units of $\mathrm{kJ} / \mathrm{mol}$ taken from [26]. Reaction $\mathrm{R}_{4 \mathrm{a}}$ is found to be a bit more exothermic than that of a similar reaction $\left(\mathrm{R}_{5}\right)$, cyclopentadienyl radical $\left(c-\mathrm{C}_{5} \mathrm{H}_{5}\right)+\mathrm{OH} \rightarrow$ cyclopentadienol $\left(c-\mathrm{C}_{5} \mathrm{H}_{5} \mathrm{OH}\right)$, the exothermicity of which is $\Delta_{\mathrm{r}, 298} \mathrm{~K} H^{\circ} \sim-304 \mathrm{~kJ} / \mathrm{mol}$ from G3B3 value [27]. 


$$
\begin{array}{rlrl}
\mathrm{C}_{3} \mathrm{H}_{5}+\mathrm{OH} & \rightarrow \mathrm{C}_{3} \mathrm{H}_{5} \mathrm{OH} & \left(\mathrm{R}_{4 \mathrm{a}}\right) \\
& \rightarrow \mathrm{C}_{2} \mathrm{H}_{3} \mathrm{CHO}+2 \mathrm{H} \\
& \rightarrow \mathrm{C}_{3} \mathrm{H}_{4}+\mathrm{H}_{2} \mathrm{O}
\end{array}
$$

The reaction of $\mathrm{OH}$ and $\mathrm{C}_{3} \mathrm{H}_{5}$ may also lead to the formation of acrolein $\left(\mathrm{C}_{2} \mathrm{H}_{3} \mathrm{CHO}\right)$ and two hydrogen atoms, reaction $\mathrm{R}_{4 b}$ [14]. Here, $\mathrm{OH}$ substitution in allyl radical weakens alpha $\mathrm{C}-\mathrm{H}$ bond which results into an alpha $\mathrm{H}$-atom elimination followed by another hydrogen release to eventually produce acrolein $\left(\mathrm{C}_{2} \mathrm{H}_{3} \mathrm{CHO}\right)$. Taking reaction analogy to $c-\mathrm{C}_{5} \mathrm{H}_{5}+\mathrm{OH} \rightarrow c-\mathrm{C}_{5} \mathrm{H}_{4} \mathrm{OH}+\mathrm{H}\left(\Delta_{\mathrm{r}, 298} \mathrm{~K} H^{\circ} \sim-16 \mathrm{~kJ} / \mathrm{mol}\right.$ [27]), ejection of the first $\mathrm{H}$-atom can also be a slight exothermic process overall. The third pathway of $\mathrm{C}_{3} \mathrm{H}_{5}+$ $\mathrm{OH}$ is a disproportionation reaction $\left(\mathrm{R}_{4 \mathrm{c}}\right)$ which leads to the formation of allene and water.

To our knowledge, there are no previous measurements for the rate coefficients of allyl $+\mathrm{OH}$. However, Tsang [14] recommended a temperature-independent value of the rate coefficients, $k_{4 a+4 b}=\left(2.5_{-1.25}^{+2.5}\right) \times$ $10^{-11} \mathrm{~cm}^{3}$ molecule $\mathrm{s}^{-1}$ for the sum of reactions $\mathrm{R}_{4 \mathrm{a}}$ and $\mathrm{R}_{4 \mathrm{~b}}$. His $\mathrm{RRKM}$ calculations revealed no fall-off effects except at the highest temperatures. According to his reports, reaction $\mathrm{R}_{4 \mathrm{~b}}$ contributes negligibly small $\left(k_{4 \mathrm{~b}} / k_{4 \mathrm{a}+4 \mathrm{~b}} \leq 0.2 \%\right)$ under our experimental conditions $(T=930-1200 \mathrm{~K}, P=1.5-2.5$ bar $) . \mathrm{He}$ further provided an estimate for reaction $\mathrm{R}_{4 \mathrm{c}}$ to be $k_{4 \mathrm{c}}=\left(1_{-0.66}^{+2.0}\right) \times 10^{-11} \mathrm{~cm}^{3}$ molecule $\mathrm{s}^{-1} \mathrm{~s}^{-1}$. Within the uncertainty, Tsang's recommendation for $k_{4 a}$ compares reasonably well with the rate coefficient of a similar reaction, $\mathrm{R}_{5}$; for example, $k_{5}(1000 \mathrm{~K}, 1 \mathrm{bar})=6.8 \times 10^{-11} \mathrm{~cm}^{3} \mathrm{molecule}^{-1} \mathrm{~s}^{-1}[27]$.

We assembled a kinetic model which consisted of $\mathrm{C}_{3} \mathrm{H}_{5}+\mathrm{OH}$ reaction $\left(\mathrm{R}_{4}\right)$ with the rate estimates from Tsang [14], Zhou et al. [28] base chemistry, Pang et al. [16] sub-chemistry for tert-butyl hydroperoxide 
(TBHP), and Lynch et al. [5] sub-chemistry for $\mathrm{C}_{3} \mathrm{H}_{5}$ radicals. We updated the rate coefficients of $\mathrm{C}_{3} \mathrm{H}_{5}+$ $\mathrm{C}_{3} \mathrm{H}_{5}$ reaction from this work.

We investigated $\mathrm{R}_{4}$ by carrying out several shock tube experiments with $\mathrm{C}_{3} \mathrm{H}_{5} \mathrm{I} / \mathrm{TBHP} / \mathrm{Ar}$ mixtures over the temperature range of $930-1200 \mathrm{~K}$ and pressures of $1.5-2.2$ bar. We monitored the reaction progress by simultaneously measuring allyl and $\mathrm{OH}$ radicals near 220 and $307 \mathrm{~nm}$, respectively. One particular set of our experiments used $\sim 10$ times higher concentration of $\mathrm{C}_{3} \mathrm{H}_{5} \mathrm{I}$ than TBHP to maintain pseudo-first order kinetics. Figure 6 shows representative time-histories for $\mathrm{OH}$ and $\mathrm{C}_{3} \mathrm{H}_{5}$ radicals. We see that $\mathrm{OH}$ reacts very quickly in excess of allyl radicals, and it decays according to pseudo-first-order kinetics. On the other hand, $\mathrm{OH}$ has negligible effect on allyl radical decay as indicated by the simulations with and without TBHP. In this case, allyl decays via self-recombination reaction by second-order kinetics. Using the assembled kinetic model, we iteratively varied the rate coefficient of reaction $\mathrm{R}_{4}$ to obtain best fits with the experimentally measured profiles. Figure 6 shows the results of such kinetic simulations with $\pm 50 \%$ perturbation from the mean value of the rate coefficient for $\mathrm{C}_{3} \mathrm{H}_{5}+\mathrm{OH} \rightarrow$ products. We computed hydroxyl sensitivity (Fig. 6S of Supplementary Material) to identify the role of secondary chemistry. It is seen that $\mathrm{OH}$ loss is most sensitive to $\mathrm{C}_{3} \mathrm{H}_{5}+\mathrm{OH}$ reaction, followed by the recombination of allyl radicals. Therefore, our measured rate coefficients $\left(k_{4}\right)$ for $\mathrm{C}_{3} \mathrm{H}_{5}+\mathrm{OH}$ reaction are highly reliable. 

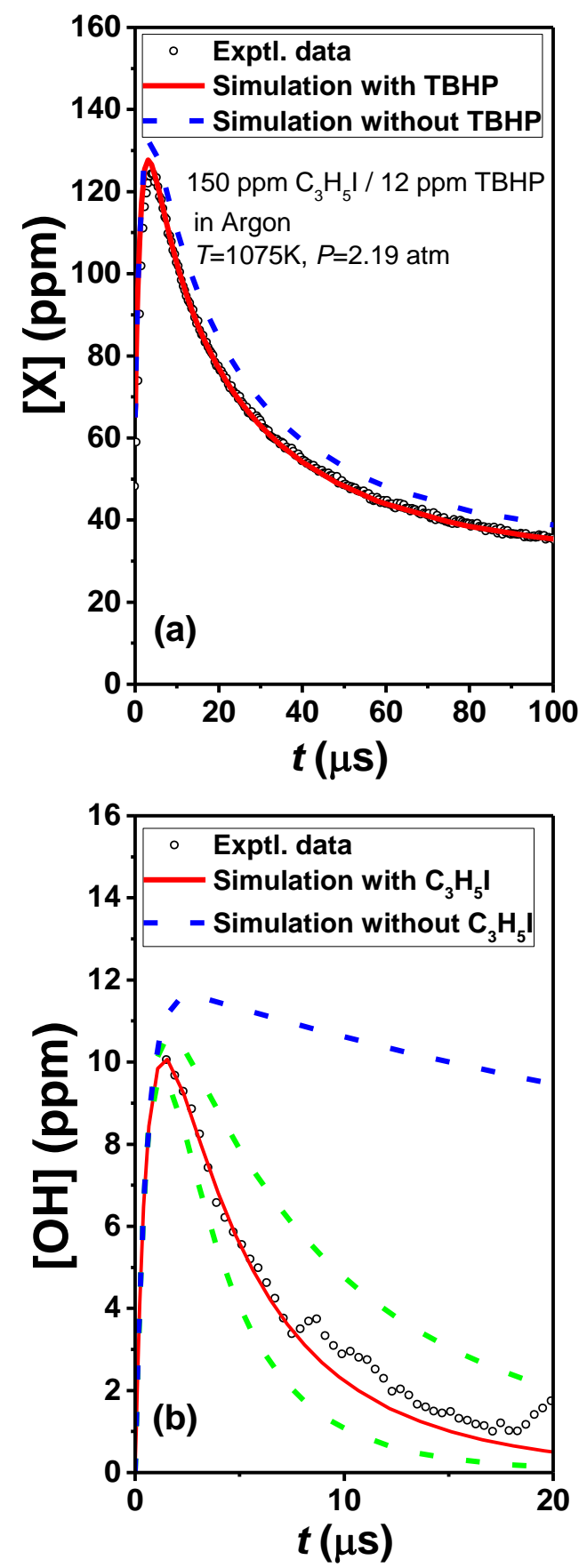

Figure 5: Mole fraction time-histories of (a) allyl and (b) $\mathrm{OH}$ radicals. Red lines represent the kinetic model with the best fit of $k_{4}=(9.9 \pm 1.7) \times 10^{-11} \mathrm{~cm}^{3}$ molecule $\mathrm{e}^{-1} \mathrm{~s}^{-1}$ for $\mathrm{C}_{3} \mathrm{H}_{5}+\mathrm{OH}$ reaction. Dashed green lines show the sensitivity of $\mathrm{C}_{3} \mathrm{H}_{5}+\mathrm{OH}$ reaction with $\pm 50 \%$ rate perturbation. 

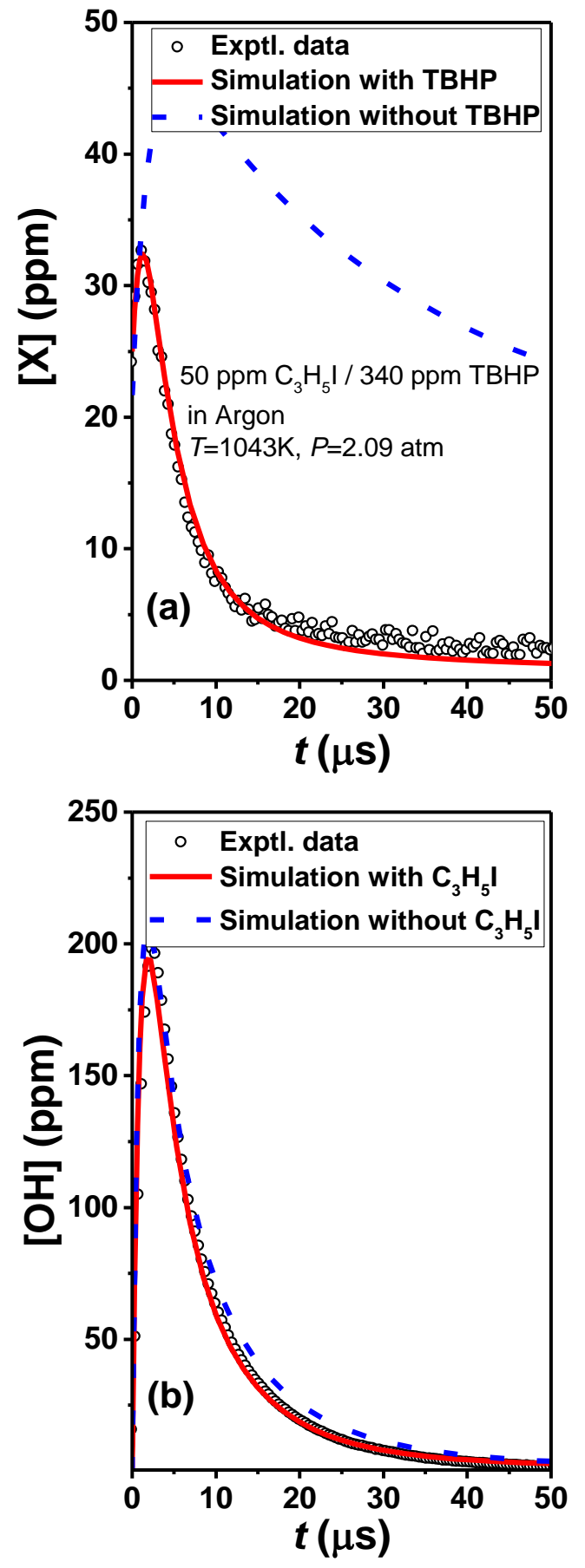

Figure 6: Mole fraction time-histories of (a) allyl and (b) $\mathrm{OH}$ radicals. The best fit resulted in $k_{4}=(9.9 \pm 4.0) \times 10^{-}$ ${ }^{11} \mathrm{~cm}^{3}$ molecule ${ }^{-1} \mathrm{~s}^{-1}$ for $\mathrm{C}_{3} \mathrm{H}_{5}+\mathrm{OH}$ reaction. 
We further assessed the reliability of $k_{4}$ by conducting several shock tube experiments with $\mathrm{OH}$ concentration much larger than allyl concentration. Figure 7 displays representative time-histories for $\mathrm{OH}$ and $\mathrm{C}_{3} \mathrm{H}_{5}$ for such a case. As can be seen, allyl radicals disappear rapidly in excess of $\mathrm{OH}$ radicals. In the absence of $\mathrm{OH}$ radicals, allyl would decay much slower as indicated by the dashed blue line in Fig. 7 (a). We note here that the rapid decrease in $\mathrm{OH}$ concentration as shown in Fig. 7 (b) is mainly due to the reaction of $\mathrm{OH}$ radicals with $\mathrm{CH}_{3}$. For the mixture used in this case, both $\mathrm{OH}$ and $\mathrm{CH}_{3}$ are produced in excess compared to $\mathrm{C}_{3} \mathrm{H}_{5}$. As can be seen by the dashed blue line in Fig. 7 (b), $\mathrm{C}_{3} \mathrm{H}_{5}$ has negligible effect on $\mathrm{OH}$ decay.

From 14 reflected-shock experiments, we obtained an average value of $(9.3 \pm 0.7) \times 10^{-11} \mathrm{~cm}^{3} \mathrm{molecule}^{-}$ ${ }^{1} \mathrm{~s}^{-1}$ for the rate coefficient of $\mathrm{C}_{3} \mathrm{H}_{5}+\mathrm{OH}$ reaction over $T=930-1200 \mathrm{~K}$ and $P=1.5-2.2$ bar. Table $3 \mathrm{~S}$ (Supplementary Materials) compiles experimentally measured rate coefficients for this reaction. Our data exhibited virtually no temperature dependence which may indicate a barrierless addition of $\mathrm{OH}$ to allyl yielding $\mathrm{C}_{3} \mathrm{H}_{5} \mathrm{OH}$ as the major initial product. The measured rate coefficients are found to be close to the collision encounter limit. We did not observe any appreciable fall-off effects within the limited pressure range of our study. As stated earlier, there are no previous measurements of this reaction to compare with. The upper limit of Tsang [14] for $k_{4}=8 \times 10^{-11} \mathrm{~cm}^{3}$ molecule $\mathrm{s}^{-1}$ agrees reasonably well with our temperature-independent value of the rate coefficient. Based on G3B3/RRKM-ME results, Robinson and Lindstedt [27] reported a rate expression, $k_{5}(T, P=1$ bar $)=4.51 \times 10^{29} T^{-11.703} \exp (-10849 / T) \mathrm{cm}^{3} \mathrm{molecule}^{-}$ ${ }^{1} \mathrm{~s}^{-1}$ for $c-\mathrm{C}_{5} \mathrm{H}_{5}+\mathrm{OH} \rightarrow c-\mathrm{C}_{5} \mathrm{H}_{5} \mathrm{OH}$ reaction $\left(\mathrm{R}_{5}\right)$. Their rate expression results in an average value of (6.2 $\pm 1.0) \times 10^{-11} \mathrm{~cm}^{3}$ molecule $\mathrm{e}^{-1} \mathrm{~s}^{-1}$ under our experimental conditions. As both $c-\mathrm{C}_{5} \mathrm{H}_{5}$ and $\mathrm{C}_{3} \mathrm{H}_{5}$ are resonantly stabilized radicals, and are likely to undergo similar reaction mechanism, one expects that they would exhibit similar reactivity with $\mathrm{OH}$ radicals. A little slower reactivity of reaction $\mathrm{R}_{5}$ than $\mathrm{R}_{4}$ may indicate that $c-\mathrm{C}_{5} \mathrm{H}_{5}$ is more thermodynamically stable than $\mathrm{C}_{3} \mathrm{H}_{5}$. For further comparison, we employed geometric 
mean rule 'GMR' [29] to estimate the rate coefficient for the cross-reaction of allyl and $\mathrm{OH}$ radicals. Using the present results for $\mathrm{C}_{3} \mathrm{H}_{5}+\mathrm{C}_{3} \mathrm{H}_{5}$ reaction and literature values for $\mathrm{OH}$ self-reaction, GMR calculations result in a temperature-independent value of $(4.0 \pm 0.1) \times 10^{-11} \mathrm{~cm}^{3} \mathrm{molecule}^{-1} \mathrm{~s}^{-1}$ for the rate coefficients of $\mathrm{C}_{3} \mathrm{H}_{5}+\mathrm{OH}$. The GMR method predicted the temperature-independence of the reaction quite well but the estimated value is lower by more than a factor of 2. While GMR method works remarkably well for the cross-reaction of hydrocarbon radicals including resonantly stabilized radicals [9, 30], it appears to make not so good predictions for polar molecules [31].

\section{Conclusions}

We employed shock tube / laser absorption technique to measure self-recombination reaction of allyl radicals and cross-reaction of allyl with hydroxyl over $930-1200 \mathrm{~K}$ and $1.1-2.2$ bar. From the measured absorption time-profiles, we determined rate coefficients for allyl iodide decomposition ( $\mathrm{R}_{1 \mathrm{a}}$ ), allyl selfrecombination $\left(\mathrm{R}_{3 \mathrm{a}}\right)$, dissociation of 1,5 -hexadiene $\left(\mathrm{R}_{-3 \mathrm{a}}\right)$ and cross-reaction of allyl and $\mathrm{OH}\left(\mathrm{R}_{4}\right)$. While the measured rate coefficients for reactions $R_{1 a}$ and $R_{-3 a}$ validated earlier studies, our rate data for allyl + allyl $\left(\mathrm{R}_{3 \mathrm{a}}\right)$ fulfilled the need of high-temperature data to resolve existing discrepancy in the literature. Our data showed a slight inverse temperature dependence but no discernible pressure effects that complemented the RRKM/ME predictions of Matsugi et al. [9] as well as the Gorin-type RRKM predictions of Lynch et al. [9]. Our work provides the first direct measurements of the rate coefficients of allyl $+\mathrm{OH}$ reaction. Measured data exhibited negligible pressure and temperature effects under our experimental conditions. This may indicate that the reaction undergoes a barrierless process leading to the formation of $\mathrm{C}_{3} \mathrm{H}_{5} \mathrm{OH}$ as the major initial product. 


\section{Acknowledgements}

Research reported in this publication was funded by King Abdullah University of Science and Technology (KAUST) under the Competitive Center Funding (CCF) program.

\section{List of Figures:}

Figure 1: A schematic of the optical set up for simultaneous detection of allyl and $\mathrm{OH}$ radicals. 6

Figure 2: Measured time-histories of allyl radicals at $220 \mathrm{~nm}$. The vertical axis of the insets is in (a) $\log$ scale and (b) reciprocal scale. 10

Figure 3: Arrhenius plot for the rate coefficient $\left(k_{3 a}\right)$ of allyl self-recombination. Figure adopted from Matsugi et al. [8] to compare with literature data.

Figure 4: Mole fraction time-histories of (a) allyl and (b) $\mathrm{OH}$ radicals. Red lines represent the kinetic model with the best fit of $k_{4}=(9.9 \pm 1.7) \times 10^{-11} \mathrm{~cm}^{3}$ molecule $\mathrm{s}^{-1}$ for $\mathrm{C}_{3} \mathrm{H}_{5}+\mathrm{OH}$ reaction. Dashed green lines show the sensitivity of $\mathrm{C}_{3} \mathrm{H}_{5}+\mathrm{OH}$ reaction with $\pm 50 \%$ rate perturbation. 16

Figure 5: Mole fraction time-histories of (a) allyl and (b) OH radicals. The best fit resulted into $k_{4}=(9.9$ $\pm 4.0) \times 10^{-11} \mathrm{~cm}^{3}$ molecule $\mathrm{e}^{-1} \mathrm{~s}^{-1}$ for $\mathrm{C}_{3} \mathrm{H}_{5}+\mathrm{OH}$ reaction 17 


\section{Supplementary Material:}

The Supplementary Material of this paper contains 3 Tables and 7 Figures.

Table 1S: Literature review of allyl self-recombination reaction.

Table 2S: Summary of the measured rate coefficients of reactions $R_{1 a}, R_{3 a}$ and $R_{-3 a}$.

Table 3S: Rate coefficients for the reaction of $\mathrm{C}_{3} \mathrm{H}_{5}$ with $\mathrm{OH}$

Figure 1S: A typical absorption-time profile recorded at $220 \mathrm{~nm}$ for a mixture of $50 \mathrm{ppm}$ allyl iodide in argon. Regions identified as 1,2 and 5 denote the pre-shock $\left(\mathrm{T}_{1}=296 \mathrm{~K}, \mathrm{P}_{1}=0.125 \mathrm{bar}\right)$, the post incident shock wave $\left(\mathrm{T}_{2}=585 \mathrm{~K}, \mathrm{P}_{2}=0.55\right.$ bar $)$ and post reflected shock $\left(\mathrm{T}_{5}=946 \mathrm{~K}, \mathrm{P}_{5}=1.66\right.$ bar $)$ regions, respectively. Time zero indicates the arrival of the reflected shock wave at the center of the optical ports. Black trace is the laser transmission signal normalized by incident laser intensity.

Figure 2S: Absorption-cross-section of allyl iodide at $220 \mathrm{~nm}$ as a function of temperature. Mean value derived is $\sigma_{220 \mathrm{~nm}}\left(\mathrm{C}_{3} \mathrm{H}_{5} \mathrm{I}, 298-800 \mathrm{~K}\right)=(1.07 \pm 0.1) \times 10^{-17} \mathrm{~cm}^{2}$ molecule ${ }^{-1}$.

Figure 3S: Absorption cross-section of allyl radical. Black line represents our recommended value given by $\sigma_{\mathrm{C} 3 \mathrm{H} 5,220 \mathrm{~nm}}(\mathrm{~T})=5.7 \cdot 10^{-17}(\mathrm{~T} / 298)^{-0.45} \mathrm{~cm}^{2}$ molecule $^{-1}$ over $298-1200 \mathrm{~K}$.

Figure $4 \mathrm{~S}: \mathrm{C}_{3} \mathrm{H}_{5}$ sensitivity analysis for $\mathrm{C}_{3} \mathrm{H}_{5}+\mathrm{C}_{3} \mathrm{H}_{5}$ reaction. The sensitivity is defined as $S_{C 3 H 5}=$ $\left(\frac{\partial X_{C_{3} H_{5}}}{\partial k_{i}}\right) *\left(\frac{k_{i}}{X_{C_{3} H_{5}}}\right)$, where $X_{C_{3} H_{5}}$ is the local $C_{3} H_{5}$ mole fraction and $k_{i}$ is the rate coefficient for the ith reaction.

Figure 5S: Arrhenius plot for the rate coefficient $\left(\mathrm{k}_{1 \mathrm{a}}\right)$ of allyl iodide decomposition. Lines are the predicted values of the rate coefficients obtained by Fridlyand et al.[6] who used Gorin-type RRKM calculations. The uncertainty associated with our data is $\pm 15 \%$.

Figure 6S: Arrhenius plots for 1,5-hexadiene $\rightarrow \mathrm{C}_{3} \mathrm{H}_{5}+\mathrm{C}_{3} \mathrm{H}_{5}$ reaction $\left(\mathrm{k}_{-3 \mathrm{a}}\right)$. Lines are the predicted values of the rate coefficients obtained by Fridlyand et al.[6] who used Gorin-type RRKM calculations. The uncertainty associated with our data is $\pm 15 \%$.

Figure 7S: Hydroxyl sensitivity analysis for $\mathrm{OH}+\mathrm{C}_{3} \mathrm{H}_{5}$ reaction. Experimental conditions: $\mathrm{T}=1075 \mathrm{~K}$ and $\mathrm{P}=2.19 \mathrm{~atm}$. Mixture composition: $150 \mathrm{ppm}_{3} \mathrm{H}_{5} \mathrm{I}$ and $12 \mathrm{ppm}$ TBHP in argon. The $\mathrm{OH}$ sensitivity is defined as $S_{O H}=\left(\frac{\partial X_{O H}}{\partial k_{i}}\right) *\left(\frac{k_{i}}{X_{O H}}\right)$, where $X_{O H}$ is the local $\mathrm{OH}$ mole fraction and $k_{i}$ is the rate coefficient for the ith reaction. 


\section{References}

1. H. Richter; J. B. Howard, Prog. Energy Combust. Sci. 26 (4) (2000) 565-608.

2. C. S. McEnally; L. D. Pfefferle; B. Atakan; K. Kohse-Höinghaus, Prog. Energy Combust. Sci. 32 (3) (2006) 247-294.

3. J. P. Senosiain; J. H. Han; C. B. Musgrave; D. M. Golden, Faraday Discuss. 119 (0) (2002) 173189.

4. D. K. Hahn; S. J. Klippenstein; J. A. Miller, Faraday Discuss. 119 (0) (2002) 79-100.

5. P. T. Lynch; C. J. Annesley; C. J. Aul; X. Yang; R. S. Tranter, J. Phys. Chem. A 117 (23) (2013) 4750-4761.

6. A. Fridlyand; P. T. Lynch; R. S. Tranter; K. Brezinsky, J. Phys. Chem. A 117 (23) (2013) 47624776.

7. M. Rossi; K. King; D. Golden, J. Am. Chem. Soc. 101 (5) (1979) 1223-1230.

8. T. M. Selby; G. Meloni; F. Goulay; S. R. Leone; A. Fahr; C. A. Taatjes; D. L. Osborn, J. Phys. Chem. A 112 (39) (2008) 9366-9373.

9. A. Matsugi; K. Suma; A. Miyoshi, J. Phys. Chem. A 115 (26) (2011) 7610-7624.

10. J. J. Throssell, Int. J. Chem. Kinet. 4 (3) (1972) 273-276.

11. D. M. Golden; N. A. Gac; S. W. Benson, J. Am. Chem. Soc. 91 (8) (1969) 2136-2137.

12. C. A. Taatjes; N. Hansen; A. McIlroy; J. A. Miller; J. P. Senosiain; S. J. Klippenstein; F. Qi, et al., Science 308 (5730) (2005) 1887-1889.

13. S. M. Burke; W. Metcalfe; O. Herbinet; F. Battin-Leclerc; F. M. Haas; J. Santner; F. L. Dryer, et al., Combust. Flame 161 (11) (2014) 2765-2784.

14. W. Tsang, J. Phys. Chem. Ref. Data 20 (2) (1991) 221-273.

15. R. X. Fernandes; B. R. Giri; H. Hippler; C. Kachiani; F. Striebel, J. Phys. Chem. A 109 (6) (2005) 1063-1070.

16. G. A. Pang; R. K. Hanson; D. M. Golden; C. T. Bowman, Z. Phys. Chem. 225 (11-12) (2011) 1157-1178.

17. R. S. Tranter; X. Yang; J. H. Kiefer, Proc. Combust.Inst 33 (1) (2011) 259-265.

18. J. Badra; A. E. Elwardany; F. Khaled; S. S. Vasu; A. Farooq, Combust. Flame 161 (3) (2014) 725734.

19. F. Khaled; B. R. Giri; A. Farooq, Proc. Combust.Inst 36 (1) (2017) 265-272. 
20. D. F. Davidson; M. Roehrig; E. L. Petersen; M. D. Di Rosa; R. K. Hanson, J. Quant. Spectrosc. Radiat. Transfer 55 (6) (1996) 755-762.

21. E. C. Rea; A. Y. Chang; R. K. Hanson, J. Quant. Spectrosc. Radiat. Transfer 37 (2) (1987) 117127.

22. H. E. van den Bergh; A. B. Callear, Trans. Faraday Soc. 66 (0) (1970) 2681-2684.

23. M. E. Jenkin; T. P. Murrells; S. J. Shalliker; G. D. Hayman, J. Chem. Soc., Faraday Trans. 89 (3) (1993) 433-446.

24. R. Boschi; D. Salahub, Mol. Phys. 24 (4) (1972) 735-752.

25. N. Nakashima; K. Yoshihara, Laser Chem. 7 (2-4) (1987) 177-196.

26. in: R. D. J. III, (Ed.) NIST Standard Reference Database Number 101: 2013.

27. R. K. Robinson; R. P. Lindstedt, Combust. Flame 158 (4) (2011) 666-686.

28. C.-W. Zhou; Y. Li; E. O'Connor; K. P. Somers; S. Thion; C. Keesee; O. Mathieu, et al., Combust. Flame 167 (2016) 353-379.

29. L. J. Garland; K. D. Bayes, J. Phys. Chem. 94 (12) (1990) 4941-4945.

30. S. J. Klippenstein; Y. Georgievskii; L. B. Harding, Phys. Chem. Chem. Phys. 8 (10) (2006) 11331147.

31. J. G. Calvert, Annu. Rev. Phys. Chem. 11 (1) (1960) 41-64. 